\title{
Analisis Statistik Dan Pemetaan Kasus Tuberkulosis Anak dan Tuberkulosis Dewasa di Kabupaten Jember Tahun 2016
}

\author{
Mochammad Choirur Roziqin', Andri Permana Wicaksono ${ }^{1}$ \\ Jurusan Kesehatan Politeknik Negeri Jember, Indonesia ${ }^{I}$ \\ e-mail:irul@polije.ac.id
}

\begin{abstract}
Tuberculosis (TB) is a contagious infectious disease that can attack various organs in the body, especially the lungs caused by Mycobacterium Tuberculosis. Tuberculosis (TB) in children can cause various cases, such as disability, cases of failure to thrive, even death. If not treated immediately, child tuberculosis at this time will show the source of tuberculosis in the future While in adults if not treated or incomplete treatment can cause dangerous complications to death. In Jember Regency, Tuberculosis sufferers occupy the second position in East Java (Data from the East Java Health Office, 2016). Therefore, this study aims to create a Geographic Information System Map of the Distribution and Statistical Analysis of Cases of Child Tuberculosis in Jember Regency in 2016 Using Google Fusion Tables. The method used is descriptive analytic with descriptive and descriptive statistical approach in the form of mapping of childhood tuberculosis. Based on the analysis carried out it can be seen the comparison between Tuberculosis cases in children with Tuberculosis cases in adult men and Tuberculosis cases in children with Tuberculosis cases in adult women who showed a significant difference. In addition, this assignment also produced a digital map of the distribution of 2016 Child Tuberculosis cases in all Districts in Jember Regency.
\end{abstract}

Keywords: google fusion tables, mapping, statistical analysis, tuberculosis

\section{Pendahuluan}

Tuberkulosis (TB) adalah penyakit infeksi menular yang dapat menyerang berbagai organ di dalam tubuh terutama paruparu. Penyakit ini disebabkan oleh bakteri Mycobacterium Tuberculosis. Penularan penyakit ini terjadi dari satu orang ke orang lain. Tuberkulosis (TB) pada anak dapat menimbulkan berbagai kasus, seperti kecacatan, kasus gagal tumbuh,bahkan kematian. Biasanya ditemukan mycobacterium (MTB) dari bahan seperti sputum, bilasan lambung, biopsi, dan lain-lain pada saat dilakukannya diagnosis. Jika tidak segera ditangani, penyakit Tuberkulosis anak pada saat ini akan menunjukkan sumber penyakit Tuberkulosis di masa datang.

Terdapat beberapa faktor yang dapat menyebabkan infeksi TB menjadi sakit TB.Faktor resiko yang pertama adalah usia. Anak berusia $\leq 5$ tahun lebih besar beresiko mengalami infeksi menjadi sakit TB karena imunitas selulernya belum berkembang sempurna (imatur). Dengan bertambahnya usia, resiko sakit TB ini akan berkurang secara bertahap. Sedangkan anak yang berusia dibawah 5 tahun beresiko lebih tinggi mengalami TB diseminata (seperti TB millier dan meningitis TB), dengan angka morbiditas dan mortalitas yang tinggi.
Sedangkan pada kasus TB dewasa, berdasarkan jenis kelamin, kasus TB padalakilaki jauh lebih tinggi daripada perempuan yaitu 1,5 kali dibandingkan dengan perempuan. Tuberculosis sebagai global emergency merupakan penyebab kematian nomor dua setelah penyakit jantung di Indonesia.

Kasus Tuberkulosis di Jember terus mengalami peningkatan baik pada anak-anak maupun dewasa. Berdasarkan data profil kesehatan kabupaten Jember tahun 2016, untuk jumlah kasus Tuberkulosis pada anak yaitu sebesar 192 sedangkan jumlah kasus Tuberkulosis pada laki-laki dewasa yaitu sebesar 1795 dan pada perempuandewasa sebesar 1520. Sehingga menempatkan Kabupaten Jember di posisi kedua dalam kasus Tuberkulosis seJawa Timur (Data Dinkes Jatim, 2016).

Oleh karena itu, untuk mengetahui perbandingan antara kasus Tuberkulosis pada anak dan dewasa di Kabupaten Jember, maka perlu dilakukan studi perbandingan antara kasus Tuberkulosis pada anak dengan kasus Tuberkulosis pada laki-laki dewasa serta kasus Tuberkulosis pada anak dengan kasus Tuberkulosis pada perempuan dewasa menggunakan statistika deskriptif. Dan dengan perkembangan teknologi yang semakin pesat ini, dapat membantu dalam 
membuat Sistem Informasi Geografis berupa pemetaan penyakit Tuberkulosis pada anak di Kabupaten Jember Tahun 2016 dengan menggunakan Google Fusion Tables. Google Fusion Tables merupakan sistem yang memberikan kemudahan dalam integrasi dan pengaturan data. Dimana, Google Fusion sebagai tempat penyimpanan data dan Google Maps sebagai media dalam menyampaikan informasi. Aplikasi yang digunakan ini diharapkan dapat menampilkan dan menyajian informasi bereferensi geografis, misalnya data yang diidentifikasi menurut lokasinya, dalam bentuk database.

\section{Metode Penelitian}

Metode penelitian ini yaitu deskriptif analitik dengan pendekatan statistik deskriptif dan deskriptif berupa pemetaan penyakit Tuberkolusis Anak Menggunakan Google Fusion Table. Data yang digunakan merupakan data sekunder yang diambil dari data profil kesehatan Kabupaten Jember tahun 2016.

\section{Hasil dan Pembahasan}

\section{Analisis Deskriptif Kasus Tuberkulosis Anak dan Tuberkulosis Dewasa di Kabupaten Jember tahun 2016}

Dalam melakukan perbandingan antara data kasus Tuberkulosis pada anak dengan kasus Tuberkulosis pada dewasa dilakukan dalam dua tahap yaitu melakukan perhitungan statistik deskriptif dan melakukanperbandingan kasus Tuberkulosis pada anak dengan kasus Tuberkulosis laki-laki dewasa serta perbandingan kasus Tuberkulosis pada anak dengan kasus Tuberkulosis perempuan dewasa.

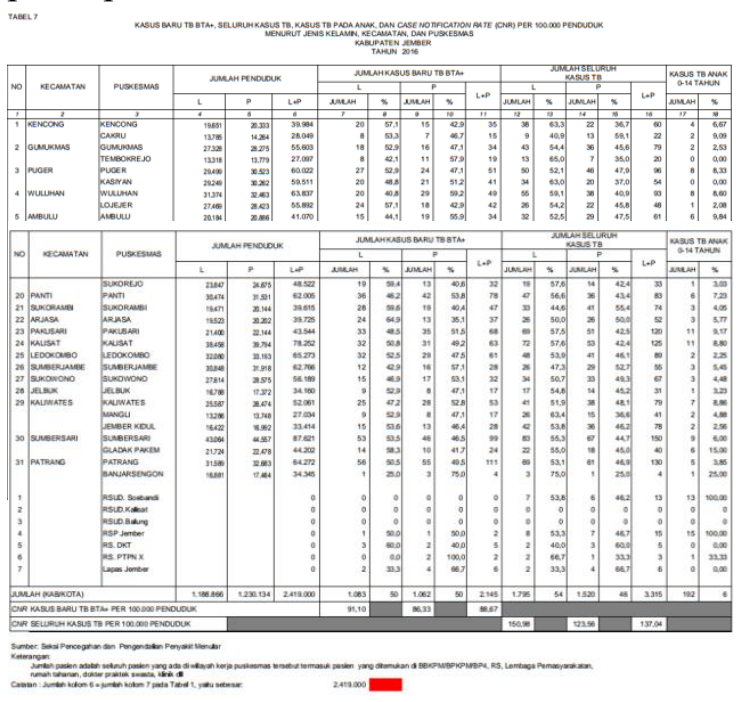

melihatkan bahwa kasus Tuberkulosis pada laki-laki dewasa memiliki jumlah yang lebih besar dibandingkan dengan kasus tuberkulosis pada perempuan dewasa dan kasus Tuberkulosis pada anak.

Sebelum melakukan perhitungan harus dilakukan uji kenormalan data terlebih dahulu untuk memastikan data yang digunakan bersifat valid dan layak. Dalam menguji kenormalan data, apabila nilai $\mathrm{p}$ value lebih besar dari 0.05 dapat dikatakan bahwa data tersebut adalah data normal namun sebaliknyaapabila nilai $p$ value lebih kecil dari 0,05 dapat dikatakan bahwa data tersebut adalah data tidak normal. Dalam penelitian ini digunakan uji Kolmogorov Smirnov untuk menguji kenormalan data.

\section{Two-Sample Kolmogorov-Smirnov}
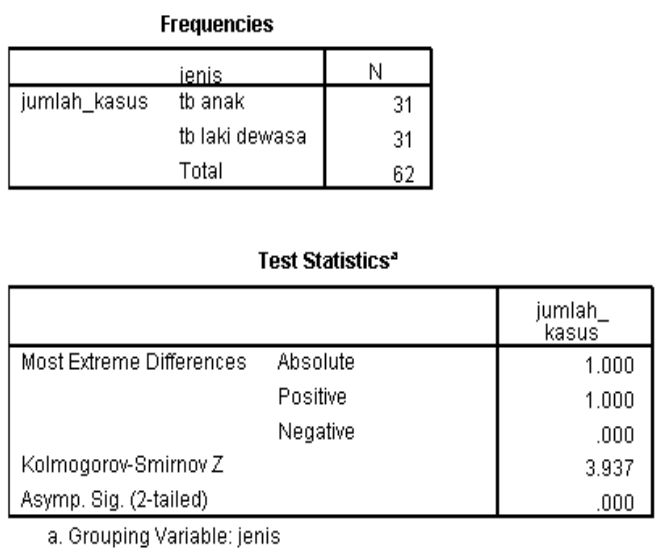

\section{Two-Sample Kolmogorov-Smirnov}

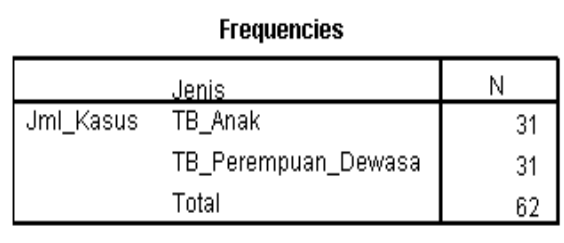

\begin{tabular}{|c|c|c|}
\hline \multicolumn{3}{|c|}{ Test Statistics ${ }^{2}$} \\
\hline & & Jml_Kasus \\
\hline Most Extreme Differences & Absolute & .968 \\
\hline & Positive & .968 \\
\hline & Negative & .000 \\
\hline Kolmogorow-Smirnov Z & & 3.810 \\
\hline Asymp. Sig. (2-tailed) & & .000 \\
\hline
\end{tabular}

Gambar 1.2 : Uji Kolmogorov Smirnov 
Berdasarkan hasil pada gambar 1.2 maka distribusi data dinyatakan memenuhi asumsi normalitas karena nilai Asymp. Sig (2tailed) atau $\mathrm{p}$ value adalah 0.0001 lebih kecil dari 0,05 maka data tersebut adalah data tidak normal. Karena data tersebut bersifat tidak normal maka dalam perhitungannya dilakukan dengan menggunakan perhitungan statistic deskriptif dan uji Man Whitney U. Sebelum melakukan perhitungan perlu dibuatnya sebuah dugaan sementara atau hipotesis tentang apa yang akan terjadi dengan hipotesis statistic :

a. Ho = tidak ada perbedaan secara signifikan antara jumlah kasus tb anak dan jumlah kasus tb laki-laki atau perempuan dewasa.

b. $\mathrm{Ha}=$ ada perbedaan secara signifikan antarajumlah kasus tb anak dan jumlah kasus tb laki-laki atau perempuan dewasa.

\begin{tabular}{|l|r|r|r|r|r|}
\multicolumn{7}{|c|}{ Descriptive Statistics } \\
\hline & \multicolumn{1}{|c|}{$N$} & \multicolumn{1}{c|}{ Mean } & Std. Deviation & Minimum & Maximum \\
\hline Jml_Kasus & 62 & 31.24 & 30.926 & 0 & 109 \\
Jenis & 62 & 1.50 & .504 & 1 & 2 \\
\hline
\end{tabular}

Mann-Whitney

\begin{tabular}{|ll|r|r|r|}
\multicolumn{6}{|c}{ Ranks } \\
\hline & Jenis & \multicolumn{1}{|c|}{$N$} & Mean Rank & Sum of Ranks \\
\hline Jml_Kasus & TB_Anak & 31 & 16.00 & 496.00 \\
& TB_Laki_Dewasa & 31 & 47.00 & 1457.00 \\
& Total & 62 & & \\
\hline
\end{tabular}

\begin{tabular}{|l|r|}
\hline \multicolumn{2}{|c|}{ Test Statistics $^{\text {s }}$} \\
\hline Mann-Whitney U & JmL_Kasus \\
\hline Milcoxon W & .000 \\
Z & 496.000 \\
Asymp. Sig. (2-tailed) & -6.771 \\
\hline \multicolumn{2}{|c|}{ a. Grouping Variable: Jenis } \\
\hline
\end{tabular}

Gambar 1.3 : uji Man Whitney U TB anak dengan TB laki dewasa

Berdasarkan hasil diatas nilai $\mathrm{p}$ adalah 0.0001 , sehingga nilai $\mathrm{p}$ lebih kecil dari 0.05 . Maka Ho ditolak, artinya ada perbedaan secara signifikan antara jumlah kasus tb anak danjumlahkasus tb laki-laki dewasa.

\begin{tabular}{|l|r|r|r|r|r|}
\hline & \multicolumn{1}{|c|}{ Descriptive Statistics } \\
\hline Jml_Kasus & 62 & \multicolumn{1}{|c|}{ Mean } & Std. Deviation & Minimum & Maximum \\
Jenis & 62 & 1.50 & 25.186 & 0 & 89 \\
\hline
\end{tabular}

Mann-Whitney

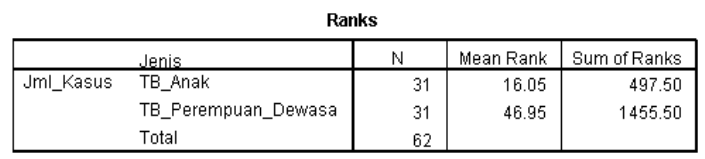

Test Statistics
\begin{tabular}{|l|r|}
\hline \multicolumn{1}{|c|}{} \\
\hline Mann-Whitney U & JmL_Kasus \\
Wilcoxon W & 1.500 \\
$Z$ & 497.500 \\
Asymp. Sig. (2-tailed) & -6.749 \\
\hline \multicolumn{2}{|c|}{ a. Grouping Variable: Jenis } \\
\hline
\end{tabular}

Gambar 1.4 : uji Man Whitney $U$ tb anak dengan tb perempuan dewasa

Berdasarkan hasil diatas nilai $\mathrm{p}$ adalah 0.0001 , sehingga nilai $\mathrm{p}$ lebih kecil dari 0.05 . Maka Ho ditolak, artinya ada perbedaan secara signifikan antara jumlah kasus tb anak dan jumlahkasustb perempuan dewasa.

Membuat sistem informasi geografis peta persebaran penyakit tuberkolusis anak di kabupaten jember pada tahun 2016 dengan menggunakan google fusion tables.

Tahap 1

Mendownload batas kecamatan dengan ekstensi .shp

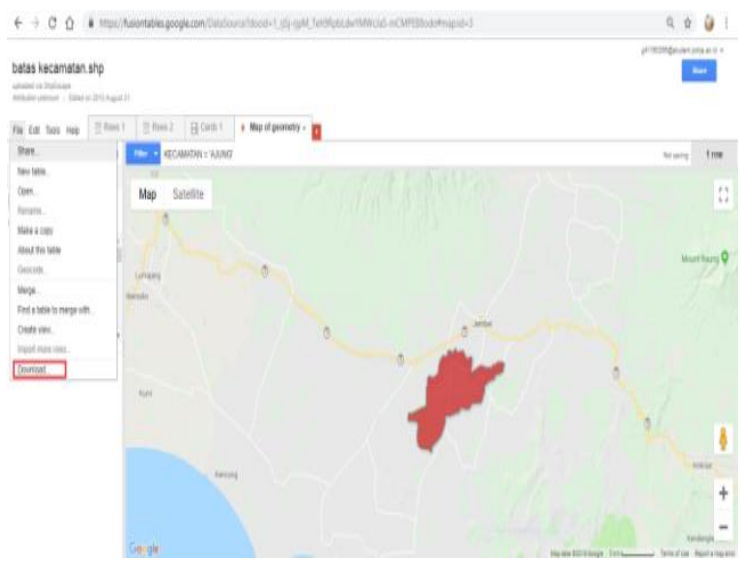




\section{Tahap 2}

Menyimpan dalam bentuk KML

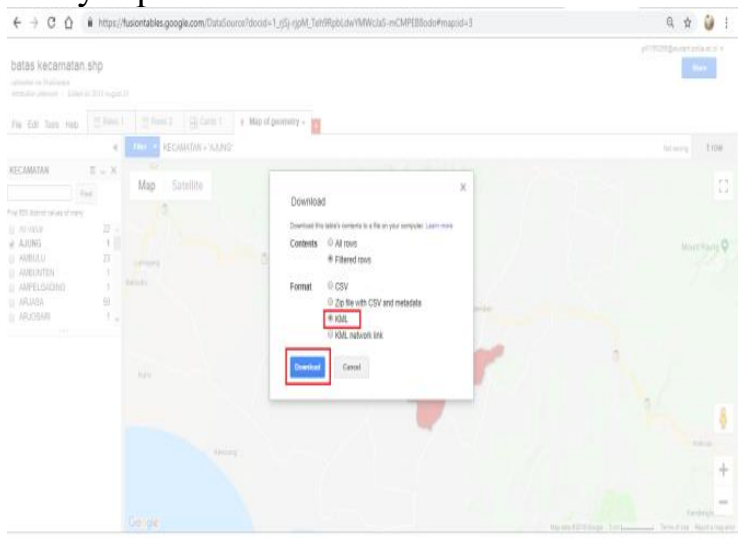

Tahap 3

Import data yang telah disimpan dalam bentuk KML

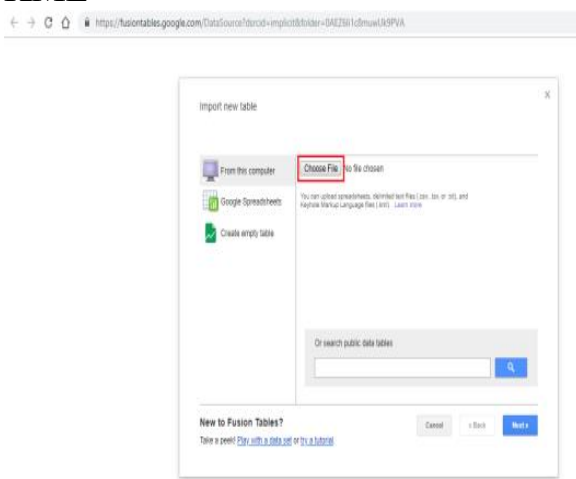

Tahap 4

Selanjutnya klik next sampai finish

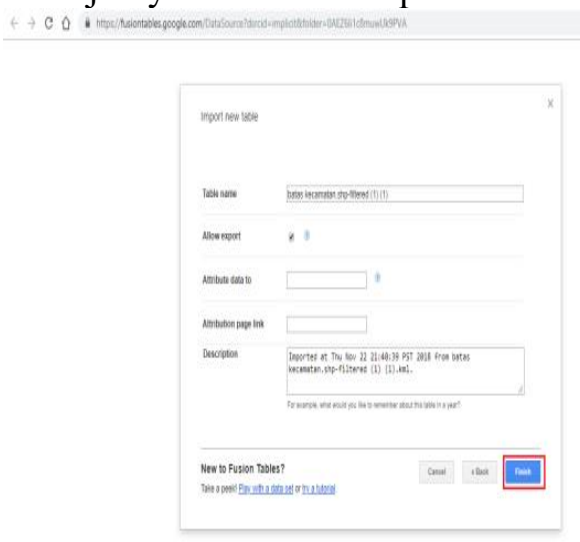

Tahap 5

Klik Map of Geometry kemudian pilih change feature styles

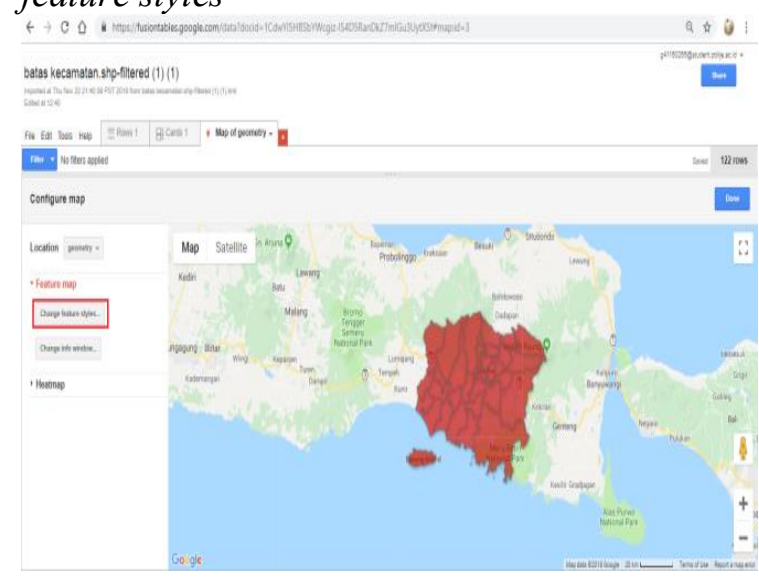

Tahap 6

Pilih fill colour untuk mengubah warna poligon kemudian save

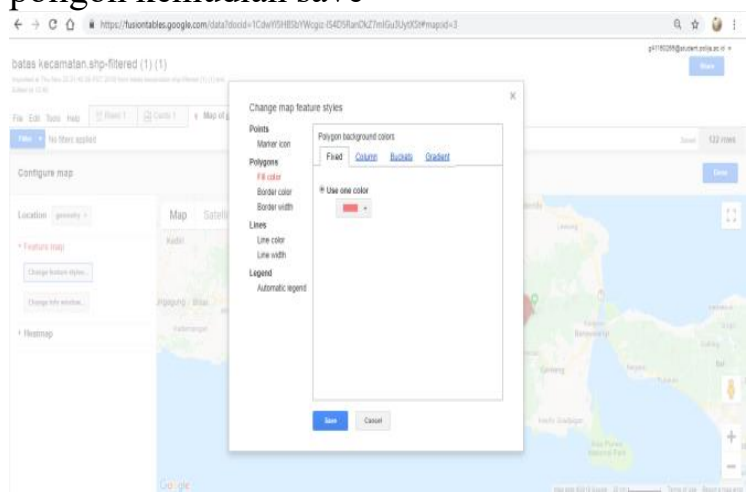

Tahap 7

Masuk google fusion tables $\rightarrow$ pilih empty table $\rightarrow$ edit $\rightarrow$ change columns $\rightarrow$ edit sesuai tampilan dibawah $\rightarrow$ save

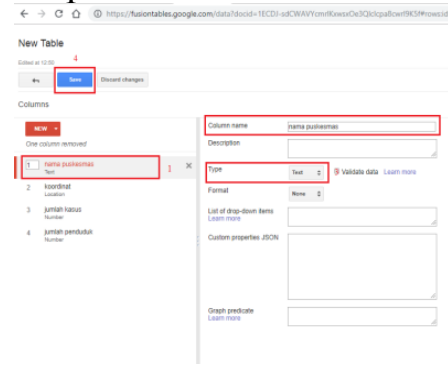


ISSN : 2354-5852

e-ISSN : 2579-5783

Tahap 8

Pilih edit $\rightarrow$ edit row $\rightarrow$ masukkan data sesuai dengan data yang dipakai $\rightarrow$ save

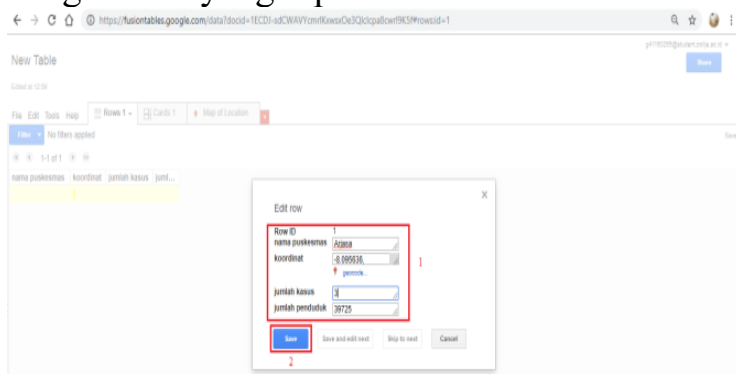

Fa. - No fass acoter

\begin{tabular}{|c|c|c|c|c|}
\hline nana pusasstat & nowdinx & jumin kas & & jumien pentusial \\
\hline Avara & 404566067172755405 & $\angle D 1$ & 3 & 3025 \\
\hline Pasiati & $41 m 12,117 \% 38$ & & 11 & ost4 \\
\hline Kostsat & -..2u190 11391966 & & 11 & $\pi 8028$ \\
\hline Lescinto & 413481,1387364 & & 2 & 65273 \\
\hline Sintejams & 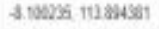 & & 2 & 6260 \\
\hline Sunems & 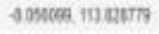 & & 3 & 98109 \\
\hline iebal & s.000686. 113.750109 & & 1 & $24+60$ \\
\hline satom & 8341286 11256654 & & 1 & 4005 \\
\hline Antasian & $+39731,136024$ & & 2 & 2042 \\
\hline Tenturilo & 8296837.713939163 & & 1 & 40032 \\
\hline curstroveid & 4.3667, 113732600 & & 0 & 28733 \\
\hline Sast & A tates in atren & & 4 & 4002 \\
\hline 80il & - В.134K3 112.878876 & & 1 & Retr \\
\hline Haver & 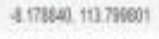 & & 1 & 50435 \\
\hline Mantuat & 42572011274565 & & 0 & ESOTE \\
\hline deropenath & 4250604 masem & & 1 & 3694 \\
\hline nom & \$275266 113.37489 & & 4 & 46954 \\
\hline wata & I Moine whastens & & 1 & cris \\
\hline
\end{tabular}

Tahap 9

Pilih Map of nama puskesmas $\rightarrow$ location coordinator $\rightarrow$ feature map $\rightarrow$ pilih change feature styles $\rightarrow$ edit sesuai gambar dibawah $\rightarrow$ save

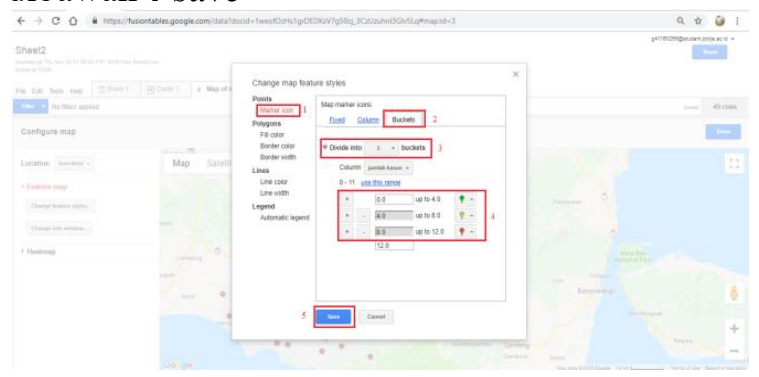

Tahap 10

Pilih Map of nama puskesmas

$\rightarrow$ location coordinator $\rightarrow$ feature map $\rightarrow$ pilih change feature $\rightarrow$ change info window $\rightarrow$ pilih data yang ingin ditampilkan seperti gambar dibawah $\rightarrow$ save

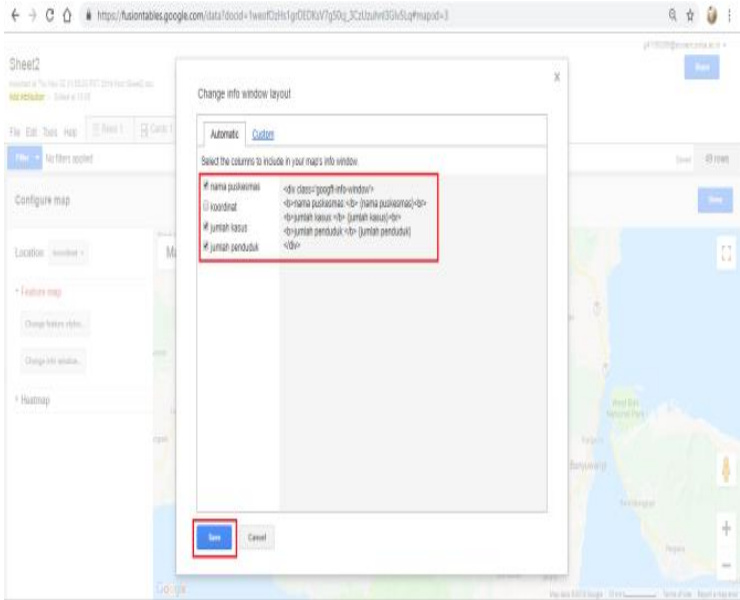

Tahap 11

Search google dan ketik layer wizard $\rightarrow$ masukkan link "batas kecamatan" dan "data tuberculosi anak" seperti gambar dibawah

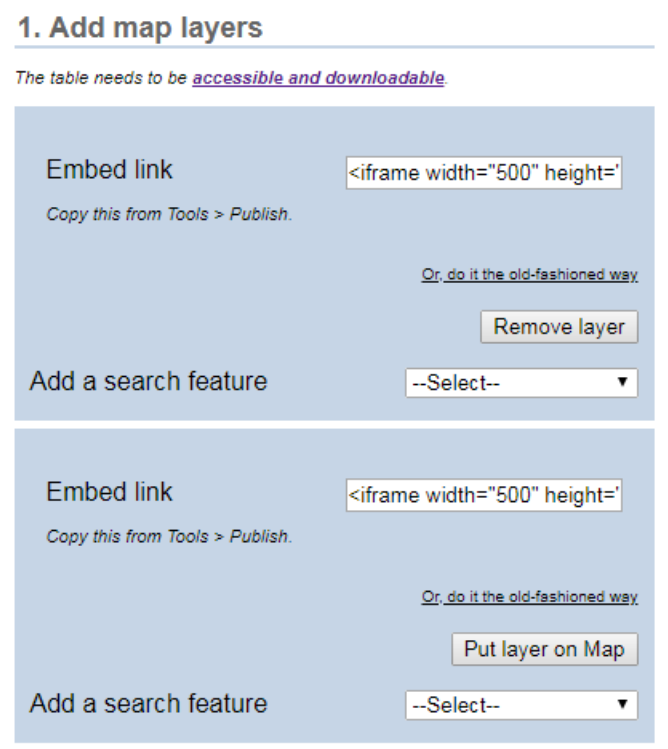

Tahap 12

Copy skrip html pada notepad kemudian simpan (.html)

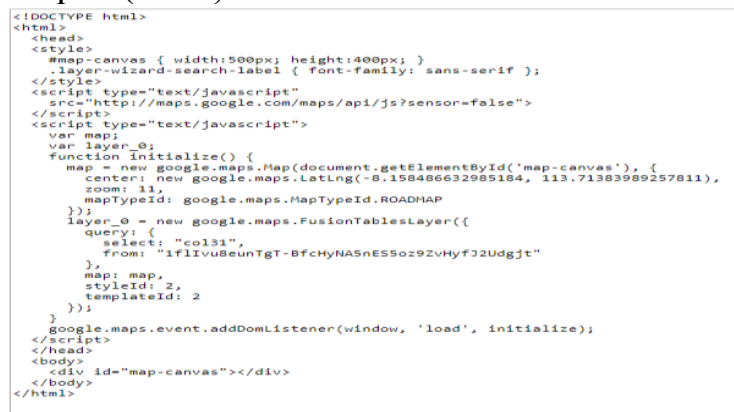


Tahap 13

Hasil output

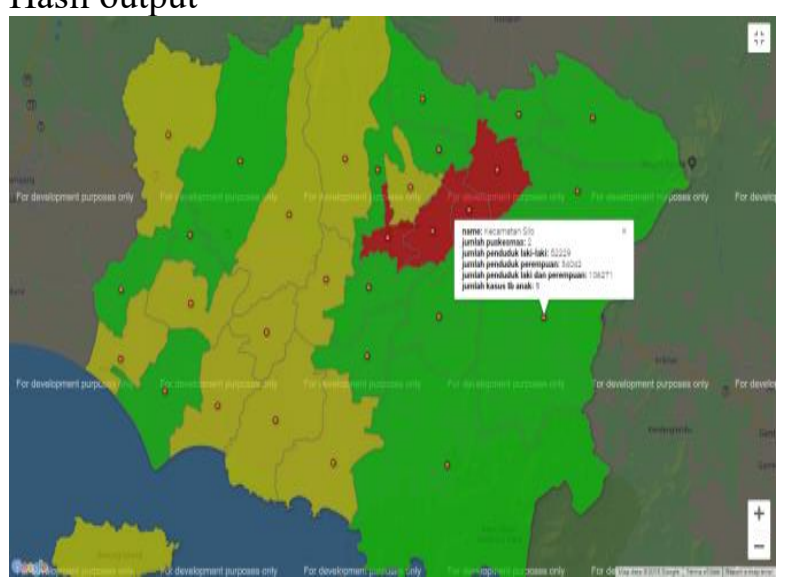

4. Simpulan dan Saran

\subsection{Simpulan}

1. Berdasarkan analisis yang dilakukan dapat diketahui perbandingan antara kasus Tuberkulosis pada anak dengan kasus Tuberkulosis pada laki-laki dewasa serta kasus Tuberkulosis pada anak dengan kasus Tuberkulosis pada perempuan dewasa yang menunjukkan adanya perbedaan yang signifikan dari kedua kasus tersebut. Dan menunjukkan bahwa kasus Tuberkulosis pada anak dapat dipengaruhi oleh Tuberkulosis pada dewasa baik laki-laki atau perempuan.

2. Peta Digital persebaran penyakit Tuberkulosis Anak pada semua kecamatan di Kabupaten Jember menampilkan data yang diperoleh dari Profil Kesehatan Kabupaten Jember Tahun 2016, meliputi jumlah penderita Tuberkulosis Anak yang mencakup data jumlah penduduk perpuskesmas, persebaran puskesmas di Kabupaten Jember yang kemudian diaplikasikan dalam bentuk Sistem Informasi Geografis.

3. Puskesmas Pakusari dan Kalisat merupakan dua puskesmas yang memiliki jumlah kasus Tuberkulosis Anak terbanyak di Kabupaten Jember dengan jumlah kasus 11.

4. Puskesmas Tembokrejo, Kasian, Curahnongko, Mumbulsari, dan Semboro merupakan lima puskesmas yang memiliki jumlah kasus Tuberkulosis Anak terbanyak di Kabupaten Jember dengan jumlah kasus 0 .

\subsection{Saran}

Perluas analisa Tuberkulosis di seluruh Puskesmas Kabupaten Jember.

\section{Daftar Pustaka}

Agrapatria, Adhikrist Soetrysno. (2016). Perancangan Dan Implementasi Aplikasi Pelaporan Perkebunan Berbasis Webgis Menggunakan Google Fusion Dan Open Data KIT. Salatiga: Universitas Kristen Satya Wacana.

Dinas Kesehatan Kabupaten Jember. (2017). Profil Kesehatan Kabupaten Jember Tahun 2016. Jember.

Dinas Kesehatan Provinsi Jawa Timur. (2016). Profil Kesehatan Provinsi Jawa Timur Tahun 2016. Surabaya.

Hikma, F, Amareta, DI, Maharani, HE. (2016). Pemetaan Persebaran Penyakit Tuberkulosis Di Kabupaten Jember Tahun 2013-2015. Jmiki Aptirmik. Volume 4, No.1, 23 November 2018.

Lemmuela, Kevin. (2015). Visualisasi Daerah Industri Salatiga Menggunakan Google Fusion Table. Salatiga: Universitas Kristen Satya Wacana.

Mochammad Choirur Roziqin. 2018. Sistem Informasi Geografis Menggunakan Quantum GIS dan dilengkapi cara upload ke web server. Yogyakarta: Graha Ilmu.

Putra, Irawan Anasta, Amelia. (2013). "Profil Tuberkulosis Pada Anak di Instalasi Rawat Jalan RSUD. Raden Mattaher Jambi”. Jurnal. Volume 1, No.1, https://online-

journal.unja.ac.id/index.php/kedokteran /article/view/2689, 23 November 2018.

Putri, Liza Amalia, dkk. (2018). Pemetaan Penyakit Tuberkulosis Pada Anak Di Kabupaten Jember Tahun 2016 
ISSN : 2354-5852

e-ISSN : 2579-5783

Menggunakan Google Fusion Tables.

Jember : Politeknik Negeri Jember. 